\title{
Entwickelung von Ammoniakgas; von
}

Ed. Harms.

Die Entwickelung von Ammoniak aus Chlorammonium oder schwefelsaurem Ammoniumoxyd ist in sofern lästig, als hierzu eine ziemlich hohe Temperatur erforderlich ist, hinreichend, um die Salze zur Verflüchtigung zu bringen. Dieser Uebelstand fällt bei Anwendung von gewöhnlichem kohlensaurem Ammoniak weg. Man vermische es mit dem 2-bis 3fachen Gewichte Kalkhydrats, schütte die Mischung in einen Kolben, überdecke mit einer nicht zu dünnen Schicht von Kalkhydrat und erwärme mässig ïber einer einfachen Spirituslampe. Die Entwickelung beginnt sogleich und kann durch Annähern oder Entfernen der Flamme leicht geleitet werden. Das Gas ist bis auf die letzte Blase frei von Kohlensäure, so dass es in Chlorbariumlösung oder Kalkwasser nicht die geringste Trübung hervorbringt.

Vielleicht ist dieses Verfahren auch für die Darstellung im Grossen brauchbar.

Das anderthalb kohlensaure Ammoniak liefert - nach der Theorie - 28,81 Proc., das Chlorammonium 30,85 Proc. Ammoniak. Beide Salze haben im Handel den nämlichen Preis. - Aetzkalk kann das Kalkhydrat nicht ersetzen.

\section{Deber Ausmittelung giftiger Alkaloide;}

R. E. A hlers in Seebaldshausen.

Bekanntlich gründet sich die Methode von Stas rdaauf, dass die sauren Salze der Alkaloide in Wasser und Weingeist löslich sind und dass, wenn man die Alkaloide durch überschüssige Alkalien in Freiheit setzt, der damit geschüttelte Aether sämmtliches Alkaloid entluält. 